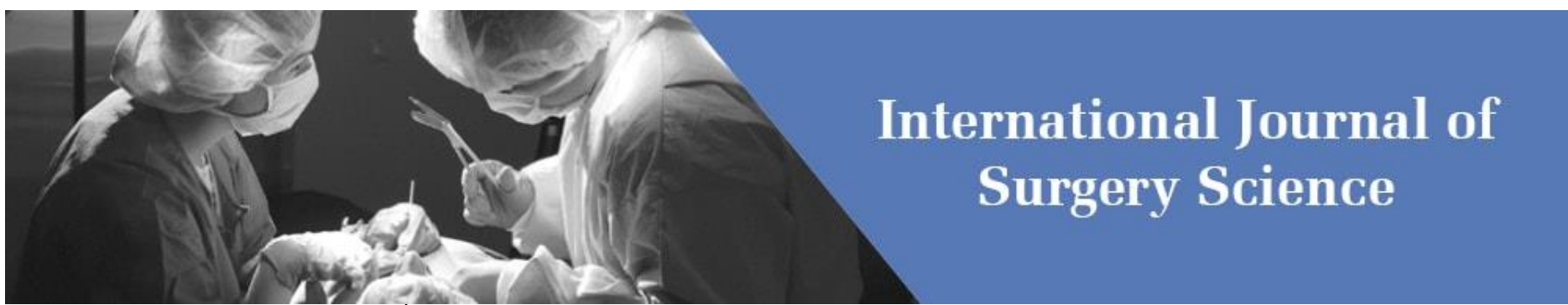

E-ISSN: 2616-3470

P-ISSN: 2616-3462

(C) Surgery Science

www.surgeryscience.com

$2019 ; 3(4): 279-281$

Received: 17-08-2019

Accepted: 22-09-2019

Ramanaiah Kayala

Assistant Professor, Department of

General Surgery, Narayana

Medical College, Nellore, Andhra

Pradesh, India

Kethireddy Vema Manasa

Intern, Department of General

Surgery, Narayana Medical

College, Nellore, Andhra Pradesh,

India

Mahidhar Reddy Venkatapuram

Professor, Department of General

Surgery, Narayana Medical

College, Nellore, Andhra Pradesh, India
Corresponding Author:

Mahidhar Reddy Venkatapuram

Professor, Department of General

Surgery, Narayana Medical

College, Nellore, Andhra Pradesh,

India

\section{Efficacy of negative pressure wound therapy when compared to gauze dressings in the management of bedsores}

\author{
Ramanaiah Kayala, Kethireddy Vema Manasa and Mahidhar Reddy \\ Venkatapuram
}

DOI: $\underline{\text { https://doi.org/10.33545/surgery.2019.v3.i4e.255 }}$

\section{Abstract}

Introduction: Bedsores contribute to the morbidity of bedridden patients and pose challenge for their rehabilitation. Newer methods are being practised and one among them is negative pressure wound therapy. This study was designed to evaluate its efficacy when compared to gauze dressings.

Objectives: To study the effectiveness of negative pressure wound dressings over gauze dressings with respect to rate of wound healing.

Materials and Methods: A prospective study was done on patients presenting with bedsores to surgery OPD at Narayana medical college. Patients were divided into two groups by random allocation wherein one group had gauze dressings and the other group underwent negative pressure wound therapy. From the time of initiation of treatment once in every week wound size and depth were measured for 6 consecutive weeks. Results were analysed.

Results: There was significant improvement in patients treated with negative pressure wound therapy with respect to wound depth and area.

Conclusion: Negative pressure wound therapy is an effective method in the management of bedsores.

Keywords: Negative pressure wood therapy, bedsores, gauze dressings

\section{Introduction}

Bedsores pose a serious challenge in management of bedridden patients contributing to morbidity and mortality in them ${ }^{[1]}$. Bedsores are the result of improper positioning which results in Ischaemia and pressure necrosis at the site of bony prominences. Elderly age, debilitating diseases like diabetes mellitus, paralysis, immunosuppressive conditions etc. aggravate bedsores [2]. Common sites are lumbosacral area, Ischial prominence, shoulder blades, occiput and heel prominence. Frequent change of position, alpha beds, frequent dressing change have been the standard methods of wound care in bedsores. Severl recent methods like alginate dressings, hydrocolloid dressings, foam dressings etc. are being tried with reports of varied success rate. Negative pressure wound therapy (NPWT) ${ }^{[3]}$ has been showing promising results in several recent studies.by continuously sucking out exudates and providing a mechanical strain (contracting force) on the cells due to negative pressure ${ }^{[4]}$, NPWT enhances wound healing. Cost wise also NPWT is very much affordable.

\section{Materials and Methods}

A prospective study was conducted during the period April 2018 to May 2019 on 50 patients who got admitted for management of bedsores at general surgery department, Narayana Medical College, Nellore, A.P., India. Patients suffering from advanced cancers, coronary artery disease, connective tissue disorders, liver failure were excluded from the study. By simple randomization patients were divided into two groups of 25 each group A patients received NPWT whereas group B patients received regular gauze dressings. In both the groups strict glycaemic control was maintained antibiotics were started based on weekly wound pus culture \& sensitivity reports underlying anaemia and hypoproteinaemia were corrected. all patients were nursed on alpha beds with frequent change of position wound depth was measured with Vernier calipers and wound area was measured for average diameter baseline readings were recorded and after that 
once in a week measurements were taken for 6 consecutive weeks. Informed consent was taken from all patients and ethics committee approval was obtained prior to study.

Statistical analysis: Latest version SPSS was used to compute numerical data and expressed as mean+/-standard deviation (SD). Ulcer area was calculated along average diameter and ulcer depth measured by vernier calipers as mentioned above in methodology. Both the readings were taken for six consecutive weeks and analysed for both the groups in comparison. $\mathrm{P}$ value less than 0.05 was considered statistically significant.

\section{Results}

Results were analyzed between group A (NPWT) and group B (gauze dressings).male preponderance was noticed in our study. Most common site of bedsore was on sacral area. Type 2 diabetes was the common medical complication in both the groups. Average age of presentation was 65years in males and 76 years in females in this study. Demographic variables of the study are tabulated below.

Table 1: The negative pressure and gauze dressing group

\begin{tabular}{|c|c|c|c|c|}
\hline & $\begin{array}{c}\text { Negative pressure wound } \\
\text { therapy group count }\end{array}$ & $\begin{array}{c}\text { Negative pressure wound therapy } \\
\text { group percent }\end{array}$ & $\begin{array}{c}\text { Gauze dressing group } \\
\text { count }\end{array}$ & $\begin{array}{c}\text { Gauze dressing group } \\
\text { percent }\end{array}$ \\
\hline a. male & 16 & $64 \%$ & 17 & $68 \%$ \\
\hline b. female & 9 & $36 \%$ & 8 & $32 \%$ \\
\hline type 1 diabetes & 1 & $4 \%$ & 25 & 0 \\
\hline Type 2 diabetes & 24 & $96 \%$ & 18 & \\
\hline sacrum & 20 & $80 \%$ & 7 & $72 \%$ \\
\hline Ischial tuberosities & 5 & $20 \%$ & $8.6 \mathrm{~cm} 2$ & \\
\hline average size of ulcer & $9.2 \mathrm{~cm} 2$ & & $7.1 \mathrm{~mm}$ & \\
\hline average depth of ulcer & $8 \mathrm{~mm}$ & & & \\
\end{tabular}

Before start of treatment the average size of the ulcer was $9.2 \mathrm{~cm} 2$ in NPWT group and it was $8.6 \mathrm{~cm} 2$ in gauze dressing group. After treatment it was $2.4 \mathrm{~cm} 2$ and $5.8 \mathrm{~cm} 2$ respectively. statistically significant difference was noticed between the two groups $(p<0.05)$ after 6 weeks of treatment.

Table 2: Show the before and after treatment

\begin{tabular}{|c|c|c|}
\hline Size of ulcer & NPWT group & Gauze dressing group \\
\hline Before treatment & $9.2 \mathrm{~cm} 2$ & $8.6 \mathrm{~cm} 2$ \\
\hline After treatment & $2.4 \mathrm{~cm} 2$ & $5.8 \mathrm{~cm} 2$ \\
\hline
\end{tabular}

The average depth of ulcer in NPWT group and Gauze dressing was $8 \mathrm{~mm} \& 7.1 \mathrm{~mm}$ respectively. After treatment it was $1.8 \mathrm{~mm}$ and $5.4 \mathrm{~mm}$ in that order. There was statistically significant difference between the two groups $(p<0.05)$ in the improvement of ulcer depth wise after treatment.

Table 3: The depth NPWT and gauze group

\begin{tabular}{|c|c|c|}
\hline Depth of ulcer & NPWT group & Gauze dressing group \\
\hline Before treatment & $8 \mathrm{~mm}$ & $7.1 \mathrm{~mm}$ \\
\hline After treatment & $1.8 \mathrm{~mm}$ & $5.4 \mathrm{~mm}$ \\
\hline
\end{tabular}

\section{Discussion}

Chronic diabetic foot ulcers bring lot of morbidity to the patient by curtailing his quality life and also pose a financial burden ${ }^{[5]}$ to the patient by hampering his work hours. Loss of limb is a traumatic experience to the patient psychologically. Among the newer methods of wound healing like hyperbaric therapy ${ }^{[6]}$, honey dressings ${ }^{[7]}$, low voltage electrical stimulation ${ }^{[8]}$, topical insulin therapy ${ }^{[9]}$ etc. negative pressure wound therapy (NPWT) is showing promising results in studies conducted at several centres. Jacobs $\mathrm{S}$ et al. ${ }^{[10]}$ in their rodent models experimented usage of negative pressure dressings Mc callon SK et al. ${ }^{[11]}$ in their study established the effectiveness of vacuum assisted closure the same results were obtained by Eginton MT et al. ${ }^{[12]}$ in their prospective randomized Trail. Plastic reconstruction of ulcers was detailed in Orgill DP ${ }^{[13]}$ reconstructive surgery abstracts.

\section{Conclusion}

Negative pressure wound therapy (NPWT) can be considered as an effective method in the management of bedsores when compared to traditional gauze dressings.

\section{References}

1. Mulder G, Armstrong D, Seaman S. Standard, appropriate, and advanced care and medical-legal considerations: Part one-diabetic foot ulcerations. Wounds. 2003; 15:92-106.

2. Fogg E. Best treatment of nonhealing and problematic wounds. JAAPA. 2009; 22(8):46-48.

3. Blume PA, Walters J, Payne W, Ayala J, Lantis J, Blume PA et al. Comparison of negative pressure wound therapy using vacuum-assisted closure with advanced moist wound therapy in the treatment of diabetic foot ulcers: A multicenter randomized controlled trial. Diabetes Care. 2008; 31:631-6.

4. McNulty A, Spranger I, Courage J, Green J, Wilkes R, Rycerz A. The consistent delivery of negative pressure to wounds using reticulated, open cell foam and regulated pressure feedback. Wounds. 2010; 22(5):114-120.

5. Raghav A, Khan ZA, Labala RK, Ahmad J, Noor S, Mishra BK. Financial burden of diabetic foot ulcers to world: a progressive topic to discuss always. Ther Adv Endocrinol Metab. 2018; 9(1):29-31. DOI:10.1177/2042018817744513

6. Bhutani S, Vishwanath G. Hyperbaric oxygen and wound healing. Indian J Plast Surg. 2012; 45(2):316-324. DOI: 10.4103/0970-0358.101309.

7. Yaghoobi R, Kazerouni A, Kazerouni O. Evidence for Clinical Use of Honey in Wound Healing as an Antibacterial, Anti-inflammatory Anti-oxidant and Anti-viral Agent: A Review. Jundishapur J Nat Pharm Prod. 2013; 8(3):100-104. DOI: 10.17795/jjnpp-9487.

8. Balakatounis KC, Angoules AG. Low-intensity electrical stimulation in wound healing: review of the efficacy of externally applied currents resembling the current of injury. Eplasty. 2008; 8:e28. Published 2008 May 16.

9. Mahidhar Reddy Venkatapuram, Ashika Reddy Padamati, Rishita M. A Study of Efficacy of Topical Insulin Therapy in the Treatment of Chronic Diabetic Foot Ulcer. Journal of Evolution of Medical and Dental Sciences, 2015, 4(68), August 24; Page: 11820-11823, DOI: $10.14260 /$ jemds/2015/1704 
10. Jacobs S, Simhaee DA, Marsano A, Fomovsky CM, Niedt $\mathrm{G}, \mathrm{Wu}$ JK. Efficacy and mechanisms of vacuum-assisted closure (VAC) therapy in promoting wound healing: a rodent model. J Plast Reconstr Aesthet Surg. 2009: 62(10):1331-1338.

11. Mc Callon SK, Knight CA, Valiulus JP, Cunningham MW, McCulloch JM, Farinas LP. Vacuum-assisted closure versus saline-moistened gauze in the healing of postoperative diabetic foot wounds. Ostomy Wound Manage. 2000; 46:28-32, 34 .

12. Eginton MT, Brown KR, Seabrook GR, Towne JB, Cambria RA. A prospective randomized evaluation of negativepressure wound dressings for diabetic foot wounds. Ann VascSurg. 2003; 17:645-9.

13. Orgill DP, Bayer LRC. Update on negative-pressure wound therapy. Plast Reconstr Surg. 2011; 127(Suppl.1):105S$115 \mathrm{~S}$. 